\title{
mPTP opening caused by Cdk5 loss is due to increased mitochondrial $\mathrm{Ca}^{2+}$ uptake
}

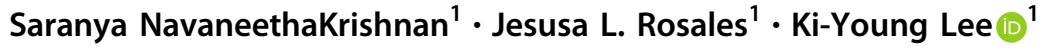

Received: 27 August 2019 / Revised: 2 January 2020 / Accepted: 23 January 2020 / Published online: 5 February 2020

(c) The Author(s) 2020. This article is published with open access

\begin{abstract}
We previously demonstrated that loss of Cdk5 in breast cancer cells promotes ROS-mediated cell death by inducing mitochondrial permeability transition pore (mPTP) opening (Oncogene 37, 1788-1804). However, the molecular mechanism by which Cdk5 loss causes mPTP opening remains to be investigated. Using primary mouse embryonic fibroblasts (MEFs) isolated from $\mathrm{Cdk5}^{-/-}$mouse embryos, we show that absence of Cdk5 causes a significant increase in both mPTP opening and mitochondrial $\mathrm{Ca}^{2+}$ level. Analysis of subcellular fractions of MEFs demonstrates that Cdk5 localizes in the mitochondria-associated endoplasmic reticulum (ER) membrane (MAM) and Cdk5 loss in MAMs causes increased ERmitochondria tethering, a process required for $\mathrm{Ca}^{2+}$ transfer from the ER to the mitochondria. Loss of Cdk5 also causes increased ATP-mediated mitochondrial $\mathrm{Ca}^{2+}$ uptake from the ER. Inhibition of ER $\mathrm{Ca}^{2+}$ release or mitochondrial $\mathrm{Ca}^{2+}$ uptake in $C d \mathrm{k}^{-/-}$MEFs prevents mPTP opening, indicating that $\mathrm{mPTP}$ opening in $C d \mathrm{k}^{-/-}$MEFs is due to increased $\mathrm{Ca}^{2+}$ transfer from the ER to the mitochondria. Altogether, our findings suggest that Cdk5 in MAMs regulates mitochondrial $\mathrm{Ca}^{2+}$ homeostasis that is disturbed upon Cdk5 loss, which leads to mPTP opening.
\end{abstract}

\section{Introduction}

Cyclin dependent kinase 5 (Cdk5) is a small prolinedirected serine/threonine kinase that serves various cell functions such as in the regulation of oxidative stress [1,2], mitochondrial functions [3] and apoptosis [4, 5]. We previously reported that loss of $\mathrm{Cdk} 5$ promotes mitochondrial permeability transition pore (mPTP)-mediated apoptosis in breast cancer cells [6]. We found that Cdk5 loss induces mPTP opening, which leads to increased cellular levels of reactive oxygen species (ROS) that subsequently cause increased susceptibility of breast cancer cells to apoptosis. However, the fundamental mechanism by which loss of Cdk5 regulates mPTP opening is unclear.

Mitochondria are cell organelles that execute a number of key cellular functions, including in energy conversion, intermediate cellular metabolism, cell differentiation,

Ki-Young Lee

kylee@ucalgary.ca

1 Departments of Cell Biology and Anatomy, Arnie Charbonneau Cancer Institute and Alberta Children's Hospital Research Institute, Cumming School of Medicine, University of Calgary, Calgary, AB, Canada immune response, calcium signaling and homeostasis, and cell death. While the outer mitochondrial membrane $(\mathrm{OMM})$ is highly permeable to $\mathrm{Ca}^{2+}$, the inner mitochondrial membrane (IMM) contains the mitochondrial calcium uniporter (MCU) complex that regulates mitochondrial calcium $\left(\left[\mathrm{Ca}^{2+}\right]_{\mathrm{mt}}\right)$ influx [7]. As MCU has low affinity to $\mathrm{Ca}^{2+}$ with $\mathrm{K}_{\mathrm{d}}$ of $\sim 10 \mu \mathrm{M}$, high $\mathrm{Ca}^{2+}$ concentration is needed for MCU activity [8]. Mitochondrial uptake of $\mathrm{Ca}^{2+}$ through MCU channels is facilitated by the close proximity of the mitochondria to the endoplasmic reticulum (ER) $[9,10]$. A common mechanism by which mitochondria communicate with the ER is through the interface between these two organelles, which is designated as the mitochondria-associated ER membrane (MAM) [11]. MAM regulates transport of lipids, calcium and other metabolites from the ER to the mitochondria [12,13], and is involved in the regulation of mitochondrial dynamics [14, 15], formation of autophagosomes and cell survival [16, 17]. MAM consists of inositol 1,4,5-trisphosphate receptors (IP3Rs), voltage-dependent anion channels (VDACs), glucoseregulated protein $75 \mathrm{kDa}$ (Grp75), glucose- regulated protein $78 \mathrm{kDa}$ (Grp78) [18], mitofusin 2 (Mfn2), long-chain fatty acid-CoA ligase 4 (FACL-4), phosphofurin acidic cluster sorting protein 2 (PACS-2), B-cell receptor-associated protein 31 (Bap31) and mitochondrial fission 1 
protein (Fis1) [19], and contains a high concentration of calcium [20]. Once $\mathrm{Ca}^{2+}$ is released from the ER to the cytoplasm via the IP3R channels, part of the released $\mathrm{Ca}^{2+}$ is taken up by the mitochondria [21] through the VDACs in the OMM, and the MCU channels in the IMM [10, 22]. Several studies show rapid $\mathrm{Ca}^{2+}$ mobilization from IP3gated channels to nearby mitochondria, resulting in increased $\left[\mathrm{Ca}^{2+}\right]_{\mathrm{mt}}$ concentration [23-25]. The ER is closely tethered to approximately $5-20 \%$ of mitochondrial surface within a $10-30 \mathrm{~nm}$ space $[26,27]$. This distinct structure is crucial for intracellular calcium homeostasis. Thus, disruption of MAM causes deregulation of calcium mobilization and disruption of $\left[\mathrm{Ca}^{2+}\right]_{\mathrm{mt}}$ homeostasis.

Under physiological conditions, a small rise in mitochondrial $\mathrm{Ca}^{2+}$ concentration leads to increased mitochondrial respiratory chain activity and ATP synthesis [28, 29]. However, pathological mitochondrial calcium overload is associated with increased generation of ROS, mitochondrial depolarization and increased or prolonged $\mathrm{mPTP}$ opening [28-30]. The voltage-dependent, high-conductance mPTP channel controls permeabilization of the IMM. While transient opening of MPTP is thought to be a calcium efflux channel in the mitochondria under normal conditions [31, 32], prolonged mPTP opening causes mitochondrial swelling and release of cytochrome $\mathrm{C}$ and other intermembrane space (IMS) proteins, leading to activation of caspase-mediated apoptosis [33, 34].

In this study, we used $C d k 5^{-/-}$mouse embryonic fibroblasts (MEFs) to investigate how Cdk5 loss induces mPTP opening. We demonstrate that loss of Cdk5 alters ERmitochondria tethering, increasing mitochondrial $\mathrm{Ca}^{2+}$ uptake from the ER. We propose that Cdk5 loss alters mitochondrial $\mathrm{Ca}^{2+}$ homeostasis, causing mPTP opening.

\section{Results}

\section{Cdk5 loss in primary MEFs induces mPTP opening}

Previously, we demonstrated that knocking down Cdk5 by siRNA in breast cancer cells causes mPTP opening and subsequent ROS increase, which promotes cell death [6]. To further characterize the molecular and cellular mechanisms that lead to mPTP opening upon Cdk5 loss, we utilized primary MEFs isolated from wt and $C d k 5^{-1-}$ mouse embryos as knockout of the $C d k 5$ gene in mice is associated with perinatal lethality [39]. Initially, we assessed mPTP opening in $C d \mathrm{~kJ}^{-/-}$MEFs by calcein-AM staining followed by treatment with $\mathrm{CoCl}_{2}$. Calcein-AM is a cell permeable fluorophore that diffuses and gets trapped in all subcellular compartments, including mitochondria [40]. Treatment with cobalt $\left(\mathrm{Co}^{2+}\right)$ quenches calcein fluorescence in all subcellular compartments except the mitochondrial matrix which is enclosed by a $\mathrm{Co}^{2+}$ impermeable inner mitochondrial membrane when mPTP is closed. Thus, the ability of $\mathrm{Co}^{2+}$ to quench mitochondrial calcein fluorescence only when MPTP is open allows determination of open vs closed status of mPTP in the cell [40]. As shown in Fig. 1a, fluorescence microscopy of wt and $C d k 5^{-/-}$MEFs following calcein staining without $\mathrm{CoCl}_{2}$ treatment showed strong and similar fluorescence intensity, indicating equivalent intracellular calcein-AM loading. However, upon treatment with $\mathrm{CoCl}_{2}, C d k 5^{-/-}$MEFs exhibited less calcein fluorescence intensity compared with wt, indicating greater quenching of mitochondrial calcein fluorescence and thus increased mPTP opening in $C d k 5^{-/-}$MEFs compared with wt. Consistent with these observations, flow cytometry analyses of $\mathrm{CoCl}_{2}$-treated cells pre-stained with calcein (Fig. 1b, top and bottom panels) showed that $C d k 5^{-/-}$ MEFs have reduced $(p<0.05)$ calcein fluorescence intensity compared to wt $(0.25$ vs 0.52$)$. The clear decline in calceinstained population of $C d \mathrm{~kJ}^{-/-}$MEFs further indicates greater mPTP opening in these cells compared with wt.

\section{Loss of Cdk5 in MEFs causes increased level of $\left[\mathrm{Ca}^{2+}\right]_{\mathrm{mt}}$}

A rise in mitochondrial $\mathrm{Ca}^{2+}$ level, $\left[\mathrm{Ca}^{2+}\right]_{\mathrm{m}}$, has been shown to be a critical regulator of mPTP opening [41]. Thus, we sought to examine potential alteration in $\left[\mathrm{Ca}^{2+}\right]_{\mathrm{mt}}$ in $C d k 5^{-/-}$ MEFs by tracing cytoplasmic $\mathrm{Ca}^{2+}$ level, $\left[\mathrm{Ca}^{2+}\right]_{\text {cyt }}$, following the addition of the protonophore and oxidative phosphorylation uncoupler, FCCP. FCCP causes depolarization or collapse of the mitochondrial membrane potential, resulting in mPTP opening and release of $\mathrm{Ca}^{2+}$ from the mitochondria [42]. Therefore, the increase in cytoplasmic $\mathrm{Ca}^{2+}$ level following FCCP treatment in wt as well as $\mathrm{Cdk5}^{-/-}$MEFs corresponds to $\left[\mathrm{Ca}^{2+}\right]_{\mathrm{mt}}$. To proceed with $\left[\mathrm{Ca}^{2+}\right]_{\mathrm{mt}}$ measurement, wt and $C d k 5^{-/-}$MEFs loaded with the cell-permeable intracellular calcium indicator, Fluo-4-AM, were subjected to single cell $\mathrm{Ca}^{2+}$ imaging before and after FCCP treatment. As shown in Fig. 2a, treatment with FCCP caused a greater wave of increase in $\left[\mathrm{Ca}^{2+}\right]_{\mathrm{cyt}}$ in $C d k 5^{-/-}$MEFs than in wt, indicating increased $\left[\mathrm{Ca}^{2+}\right]_{\mathrm{mt}}$ in $\mathrm{Cdk5^{-/ }}$ MEFs compared with wt. Quantitative analyses revealed a 58\% increase $(p<0.05)$ in peak amplitude (Fig. 2b) and a twofold increase $(p<0.05)$ in area under the curve (Fig. 2c) in $C d k 5^{-1-}$ MEFs compared with wt further indicating increased $\left[\mathrm{Ca}^{2+}\right]_{\mathrm{mt}}$ in $C d k 5^{-/-}$ MEFs.

\section{Cdk5 is a mitochondria-associated ER membrane (MAM) protein, which when lost induces ER- mitochondria tethering}

The ER is the major intracellular $\mathrm{Ca}^{2+}$ store, and the interface between the ER and the mitochondria, named mitochondria-associated ER membrane (MAM), contains 
A

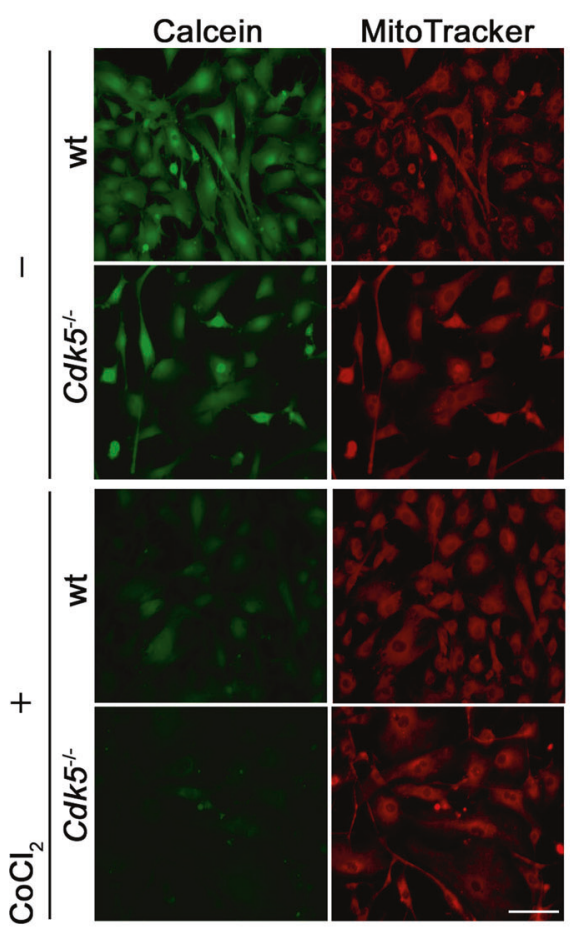

B
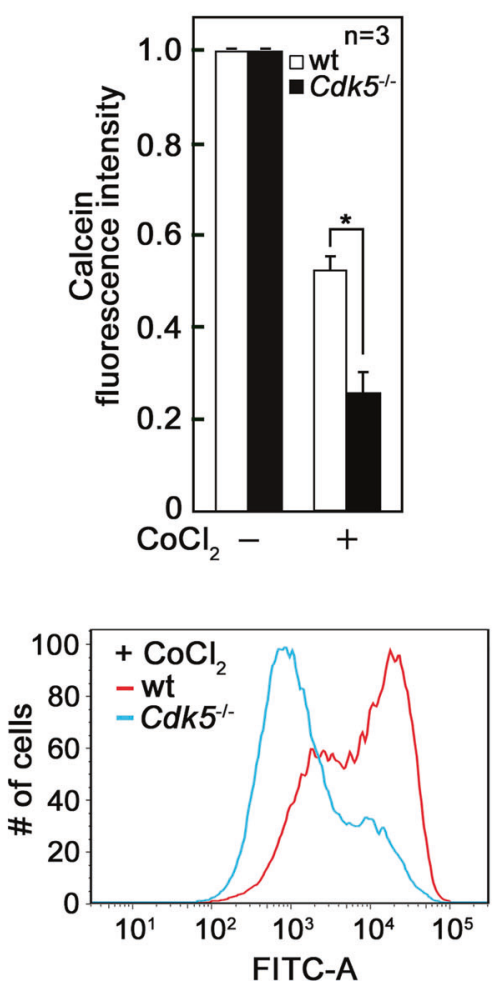

with calcein-AM alone were normalized to 1.0. The relative calcein fluorescence intensity in MEFs treated with $\mathrm{CoCl}_{2}$ were then calculated. Values are means \pm SEM from three $(n=3)$ independent experiments. For each experiment, $1 \times 10^{4}$ cells were used for flow cytometry analysis. ${ }^{*} p<0.05$ by unpaired Student's $t$ test. c Wt and $C d k 5^{-/-}$MEFs loaded with calcein-AM were treated with $\mathrm{CoCl}_{2}$ and subjected to flow cytometry analysis. Data represent one of three $(n=$ 3) independent experiments showing similar results.

mitochondria $[43,45,46]$, we analyzed these parameters in wt and $C d k 5^{-1-}$ MEFs. As shown in Fig. 3c, the percentage of mitochondria that is in contact with the ER is higher $(p<0.05)$ in $C d k 5^{-1-}$ MEFs than in wt $(67 \%$ vs $52 \%)$. Figure $3 \mathrm{~d}$ shows that the mitochondrial perimeter that is in contact with the ER in $C d k 5^{-1-}$ MEFs is also greater $(p<$ $0.01)$ in $C d k 5^{-/-}$MEFs than in wt ( $40 \%$ vs $\left.15 \%\right)$. In addition, as shown in Fig. 3e, the percentage of ER-mitochondria contact sites with a distance of $<30 \mathrm{~nm}$ is higher $(p<0.05)$ in $C d k 5^{-1-}$ MEFs compared with wt (44\% vs $25 \%$ ).

\section{Loss of Cdk5 causes increased mitochondrial $\mathrm{Ca}^{2+}$ uptake from the ER upon stimulation with ATP}

Our next approach was to examine a potential difference in mitochondrial $\mathrm{Ca}^{2+}$ uptake from the ER in wt and $\mathrm{Cdk5^{-/ }}$ MEFs. To do so, cells in $\mathrm{Ca}^{2+}$-free buffer and pre-loaded with a mitochondrial $\mathrm{Ca}^{2+}$ probe, Rhod-2 AM [47], were treated with ATP, which binds cell surface purinergic receptors [48] and IP3R [49], which both stimulate have been shown to influence $\mathrm{ER} \mathrm{Ca}^{2+}$ transfer to the 
IP3-evoked ER $\mathrm{Ca}^{2+}$ release [49]. As shown in Fig. 4a, treatment with ATP caused a greater wave of increase in $\left[\mathrm{Ca}^{2+}\right]_{\mathrm{mt}}$ in $C d \mathrm{~kJ}^{-/-}$MEFs than in wt. Quantitative analyses showed a $26 \%$ increase $(p<0.05)$ in peak amplitude (Fig. 4b), and a $69 \%$ increase in integrated $\mathrm{Ca}^{2+}$ signal (Fig. 4c) in $\mathrm{Cdk}^{-1-}$ MEFs compared to wt. In addition, the rate of $\mathrm{Ca}^{2+}$ influx into the mitochondria was $33 \%$ faster in $C d \mathrm{k5}^{-/-}$MEFs compared to wt (Fig. 4d) while the rate of $\mathrm{Ca}^{2+}$ extrusion from the mitochondria was slower by $75 \%$ in $C d k 5^{-/-}$MEFs compared to wt (Fig. 4e). Together, our data indicate that $C d k 5^{-1-}$ MEFs have increased and prolonged ATP-induced mitochondrial $\mathrm{Ca}^{2+}$ uptake from the ER compared to wt.

\section{mPTP opening due to Cdk5 loss is blocked by inhibition of $\mathrm{ER} \mathrm{Ca}^{2+}$ release or mitochondrial calcium uptake}

We then investigated whether inhibition of either $\mathrm{ER} \mathrm{Ca}^{2+}$ release with the potent IP3R inhibitor, $\mathrm{XeC}[50,51]$, or mitochondrial calcium uptake with the potent MCU inhibitor, RuR [52], followed by calcein-AM loading and subsequent treatment with $\mathrm{CoCl}_{2}$ would show blockade of increased mPTP opening in $C d k 5^{-/-}$MEFs. Consistent with our data in Fig. 1, flow cytometry analyses shown in Fig. 5, a, b demonstrate that $C d k 5^{-/}$MEFs exhibited less calcein fluorescence intensity compared to wt, indicating greater $\mathrm{Co}^{2+}$ quenching of mitochondrial calcein fluorescence and thus increased mPTP opening in $C d k 5^{-/}$MEFs compared to wt. However, treatment with $\mathrm{XeC}$ or RuR increased the calcein fluorescence intensity in $C d k 5^{-/-}$MEFs to a level equivalent to that of wt. Treatment with the potent mPTP desensitizers, CsA [53] or SFA [54] also completely prevented mPTP opening in $C d k^{-/}$MEFs. Cells untreated with $\mathrm{CoCl}_{2}$ and cells treated with ionomycin served as controls. Altogether, we demonstrate that inhibition of either $\mathrm{ER} \mathrm{Ca}^{2+}$ release or mitochondrial calcium uptake prevents $\mathrm{mPTP}$ opening in $\mathrm{Cdk5^{-/ }} \mathrm{MEFs}$, further indicating that $\mathrm{mPTP}$ opening due to loss of Cdk5 results from increased $\mathrm{ER} \mathrm{Ca}^{2+}$ transfer to mitochondria.

\section{Discussion}

We now know that loss of Cdk5 in breast cancer cells causes increased MPTP opening that is associated with mitochondrial depolarization, increased ROS levels, mitochondrial fragmentation and apoptosis [6]. Furthermore, we determined that the MPTP-mediated apoptotic pathway in breast cancer cells is coupled with an increase in both intracellular $\left[\mathrm{Ca}^{2+}\right]$ level and calcineurin activity [6]. In the current study, we identify a novel mechanism by which loss of Cdk5 promotes mPTP opening. Figure 6 illustrates that
A

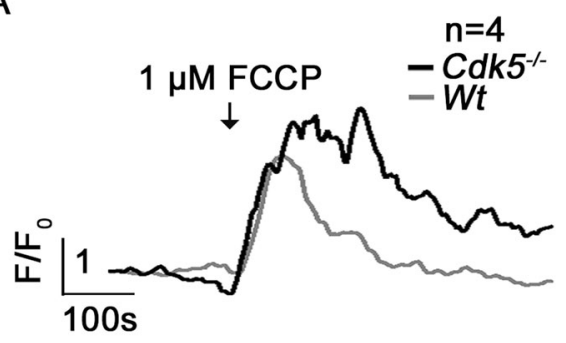

B

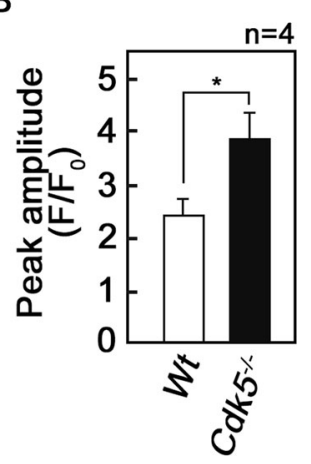

C

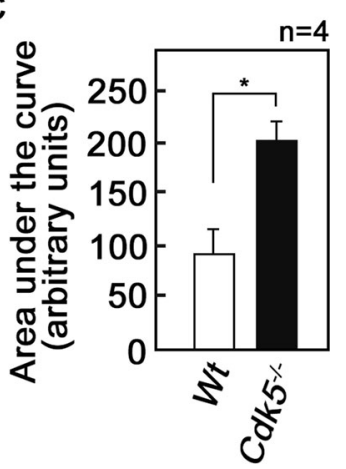

Fig. 2 Loss of Cdk5 causes increased mitochondrial $\mathrm{Ca}^{2+}$ level. MEFs were isolated from wt and $C d k 5^{-/-}$embryos from $C d k 5^{+/-}$ pregnant female mice. Cells loaded with Fluo-4 AM $(5 \mu \mathrm{M})$ were subjected to single-cell $\mathrm{Ca}^{2+}$ imaging in $\mathrm{Ca}^{2+}$ free buffer. Carbonyl cyanide-p-trifluoromethoxyphenylhydrazone (FCCP, $1 \mu \mathrm{M}$ ) was added where indicated. a FCCP-induced $\mathrm{Ca}^{2+}$ flux to the cytoplasm is greater in $C d k 5^{-/-}$MEFs than in wt MEFs. Mean values of $\mathrm{Ca}^{2+}$ signals from 15 randomly selected cells from each genotype are shown. Data represent results from one of four independent experiments $(n=4)$ showing a similar staining patterns. Analysis of results from all four independent experiments, each with data from 15 randomly selected cells from wt and $C d k 5^{-/-}$MEFs, revealed that: $\mathbf{b}$ the peak amplitudes $\left(F / F_{0}\right)$ of $\mathrm{Ca}^{2+}$ response to FCCP is higher in $C d k 5^{-1-}$ MEFs than in wt, and (c) the integrated $\mathrm{Ca}^{2+}$ signals (area under the curve from 180 to $600 \mathrm{~s}$ ) in response to FCCP is also higher in $\mathrm{Cdk} 5^{-/-}$MEFs than in wt, indicating greater $\mathrm{Ca}^{2}$ flux to the cytoplasm due to increased stored $\left[\mathrm{Ca}^{2+}\right]_{\mathrm{mt}}$ in $\mathrm{Cdk}^{-/-}$MEFs compared with wt. MEFs obtained from two different sets of wt and $\mathrm{Cdk} 5^{-/-}$embryos were used at passage $2-7$. Values are means \pm SEM from the four independent experiments. $* p<0.05$ by unpaired Student's $t$ test.

Cdk5 loss in $C d \mathrm{k}^{-/-}$MEFs causes an increase in number and length of ER-mitochondrial contact sites as well as a decrease in gaps between these contact sites. These changes promote an increase in mitochondrial $\mathrm{Ca}^{2+}$ uptake from the ER, causing increased $\left[\mathrm{Ca}^{2+}\right]_{\mathrm{mt}}$ and subsequent increase in mPTP opening upon loss of Cdk5.

mPTP is a calcium-dependent and CsA-sensitive highconductance channel. mPTP opening induces permeability of the IMM due to the opening of its pore forming proteins. The components of $\mathrm{mPTP}$ and the pore-forming proteins remain unresolved. Nonetheless, several studies implicate physiological roles of mPTP in $\mathrm{Ca}^{2+}$ buffering, energy metabolism, and mitochondrial homeostasis. Our group [6] and others $[33,34,55,56]$ also showed that increased or prolonged mPTP opening results in mitochondrial depolarization, 
A
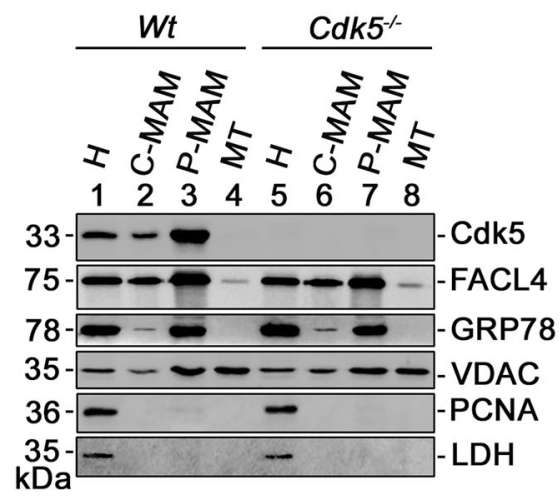

B

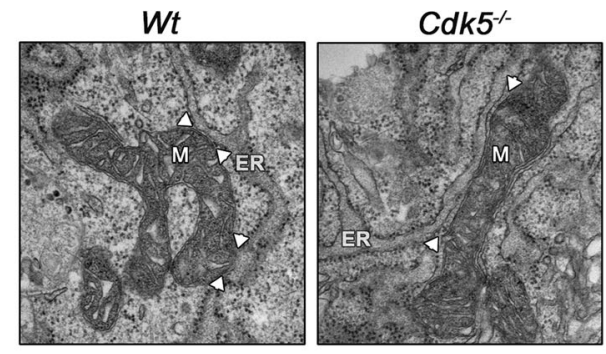

C

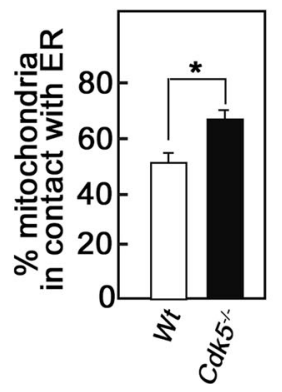

D

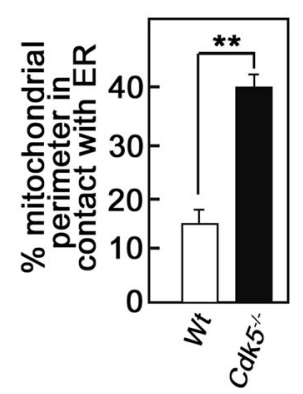

E

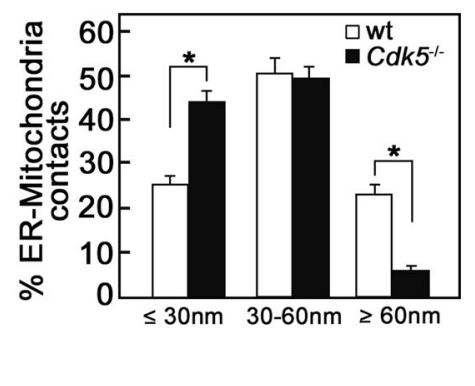

Fig. 3 Cdk5 localizes in MAMs and loss of Cdk5 causes increased number and length of ER-mitochondria contact sites and reduced contact distance between these two organelles. a Immunoblot analysis of purified MAM and mitochondria in wt and $C d k 5^{-/-}$MEFs. $50 \mu$ l of homogenate $(\mathrm{H})$, crude MAM (C-MAM), purified MAM (P$\mathrm{MAM}$ ), and purified mitochondria (MT) were loaded. For subcellular markers, fatty acid-CoA ligase, long-chain (FACL4) and glucoseregulated protein $78 \mathrm{kDa}$ (GRP78) were used for ER-MAM; VDAC for mitochondria-MAM; proliferating cell nuclear antigen (PCNA) for nucleus; and lactate dehydrogenase (LDH) for cytoplasm. Blots shown represent data from one of three independent experiments $(n=3)$ showing similar results. b-e Transmission electron microscopy (TEM) of ER-mitochondria tethering in wt and $C d \mathrm{~kJ}^{-/-}$MEFs. Images were acquired using a Hitachi H7650 TEM. Scale bar $=100 \mathrm{~nm}$. ER: endoplasmic reticulum; M: mitochondria. Arrowheads are directed at ER-mitochondria contact sites. For the morphometric analysis in $\mathbf{c}-\mathbf{e}, \mathbf{a}$ total of six TEM grids ( $3.05 \mathrm{~mm}$ discs) prepared from two embeddings per genotype were analyzed: four grids from embedding 1 and two

increased ROS generation, inhibition of ATP synthesis, and release of apoptosis-inducing mitochondrial proteins such as cytochrome $\mathrm{C}$ and apoptosis inducing factor, causing activation of the caspase-mediated apoptotic pathway. We observed these $\mathrm{mPTP}$ opening-induced characteristics in breast cancer grids from embedding 2. Mitochondrial counts and mitochondria-ER contact measurements were performed in groups of two grids $(n=3$, where replicates 1 and 2 originate from the four grids from embedding 1 and replicate 3 originates from the two grids from embedding 2 . In $\mathbf{c}$, all observed mitochondria in wt and $C d k 5^{-1-}$ MEFs, irrespective of the number of cells, were counted and the percentage of mitochondria in contact with ER was calculated. In $\mathbf{d}$, the mitochondrial perimeter in contact with ER was measured and the percentage of the total individual mitochondrial perimeter in contact with ER was calculated. In e, distances between ER and mitochondria in contact sites were measured and the percentage of the total contact sites with different ranges of ER-mitochondria distances were calculated. In $\mathbf{d}$ and $\mathbf{e}$, a total of at least 40 ER-mitochondria contacts, irrespective of the number of cells, were analyzed per two TEM grids (i.e., at least 120 ER-mitochondria contacts were analyzed per genotype).). Embeddings were from different cultures of MEFs. Values are means $\pm \mathrm{SEM}$; $n=3 ; * p<0.05$ and ${ }^{*} p<0.01$ by unpaired Student's $t$ test.

cells lacking Cdk5 but $C d \mathrm{k5}^{-/-}$MEFs also exhibit increased $\mathrm{mPTP}$ opening, which is reversed by $\mathrm{mPTP}$ desensitizers such as CsA and SFA and show increased $\left[\mathrm{Ca}^{2+}\right]_{\mathrm{mt}}$ level that has been shown to induce mPTP opening. As with breast cancer cells depleted of Cdk5 by siRNA, we determined here that 
A

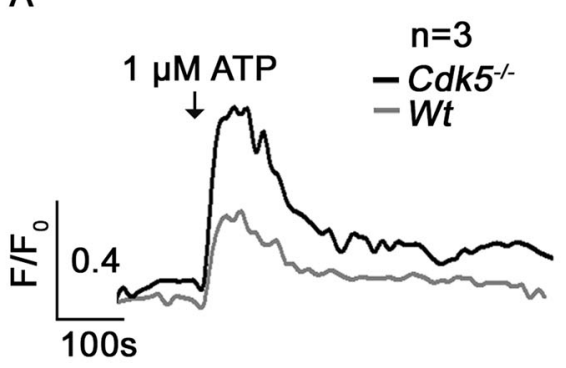

B

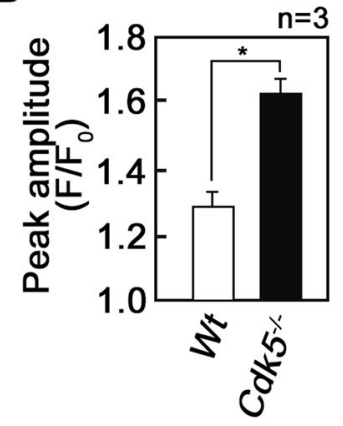

E

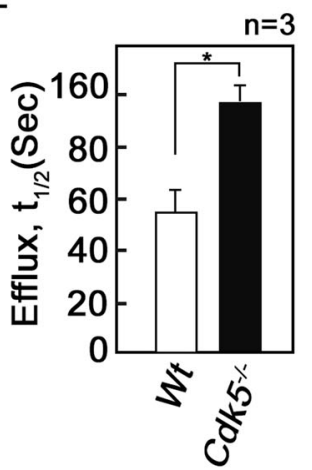

Fig. 4 Stimulation with ATP causes greater mitochondrial $\mathrm{Ca}^{2+}$ uptake from the ER in $\mathrm{Cdk5}^{-1-}$ MEFs compared to wt. a Wt and $C d k 5^{-1-}$ MEFs loaded with Rhod-2 AM $(5 \mu \mathrm{M})$ for 30 min in $\mathrm{Ca}^{2+}$ free buffer were analysed by single cell $\mathrm{Ca}^{2+}$ imaging. ATP $(1 \mu \mathrm{M})$ was added where indicated. Data show mean values of $\mathrm{Ca}^{2+}$ signals from 15 randomly selected cells and represent one of three independent experiments showing a similar results. Analysis of results from the three independent experiments $(n=3)$, each with data from 10-15

$C d k 5^{-/-}$MEFs exhibit increased mPTP opening that is reversed by the mPTP desensitizers, CsA and SFA, and show increased $\left[\mathrm{Ca}^{2+}\right]_{\mathrm{mt}}$ level that induces mPTP opening. It is interesting, however, that while loss of Cdk5 in breast cancer cells promote apoptosis, we observed that $C d k 5^{-1-}$ MEFs show increased proliferation (data not shown). This was unexpected but supports differential physiology and roles of Cdk5 in normal and cancer cells, and calls for more comprehensive investigations on the function of $\mathrm{Cdk} 5$ in mitochondrial calcium dynamics in normal and disease conditions.

MAM, a proteinaceous link between the ER and mitochondria, is important for calcium and metabolite transfer between these organelles. In this study, we show that Cdk5 is enriched in pure MAM fractions, a finding that is consistent with the mass spectrometry analysis by Poston et al., identifying, with high confidence, $\mathrm{Cdk} 5$ as one of the MAM proteins in mouse brain [57]. For effective calcium transfer, MCU channels require close ER-mitochondria apposition that is influenced by the ER-mitochondria contact site number, length and distance. The ER-mitochondria contact sites allow the rapid transfer of large amounts of $\mathrm{Ca}^{2+}$ from randomly selected cells from each genotype, showed that compared to wt, $C d k 5^{-/-}$MEFs exhibited: b higher peak amplitude $\left(F / F_{0}\right)$, corresponding to greater $\mathrm{Ca}^{2+}$ influx into the mitochondria; $\mathbf{c}$ increased integrated $\mathrm{Ca}^{2+}$ signals (area under the curve from 120 to $600 \mathrm{~s}$ ), which also indicates elevated $\mathrm{Ca}^{2+}$ entry into the mitochondria; d reduced time of $\mathrm{Ca}^{2+}$ influx into mitochondria, indicating faster rate of influx; and $\mathbf{e}$ increased time of efflux, indicating slower rate of efflux. Values are means \pm SEM. ${ }^{*} p<0.05$ by unpaired Student's $t$ test.

the ER to the mitochondria upon opening of the $\mathrm{IP}_{3}$-gated channels $[23,24,58]$. The distance from the OMM to the rough and smooth ER was determined to be $10-30 \mathrm{~nm}$ and 9-16 $\mathrm{nm}$ respectively [45, 59], and about $5-20 \%$ of the mitochondrial surface is closely apposed to the ER [26, 27]. Our studies show that in wt cells, the ER is juxtaposed to $15 \%$ of the mitochondrial surface whereas loss of Cdk5 increases the ER-mitochondrial juxtaposition to about $40 \%$. Similarly, the percentage of ER-mitochondria contacts within $\leq 30 \mathrm{~nm}$ is higher in the absence of Cdk5. Since disruption in ER-mitochondria tethering alters $\mathrm{Ca}^{2+}$ transfer between the ER and the mitochondria [60], it is not surprising that we observed increased ATP-induced mitochondrial calcium uptake in cells lacking Cdk5. Similarly, prolonged extrusion of mitochondrial $\mathrm{Ca}^{2+}$ in the absence of $\mathrm{Cdk} 5$ is expected to contribute to $\left[\mathrm{Ca}^{2+}\right]_{\mathrm{mt}}$ accumulation and subsequent mPTP opening. Nevertheless, our observations indicate that $\mathrm{Cdk} 5$ in MAM serves to control ERmitochondrial tethering, and loss of Cdk5 causes an upsurge in mitochondrial calcium uptake by increasing ERmitochondrial tethering. While studies are underway to 
A
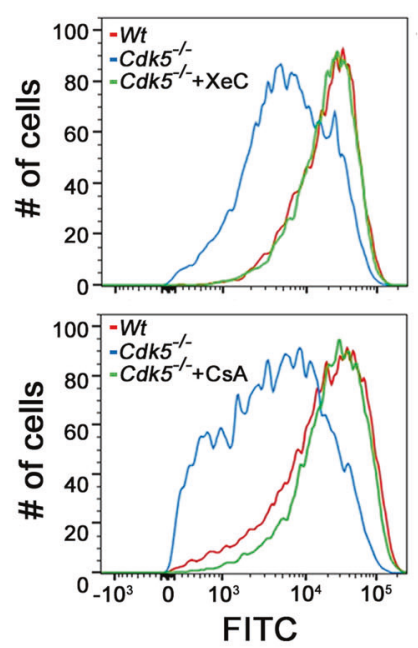

B

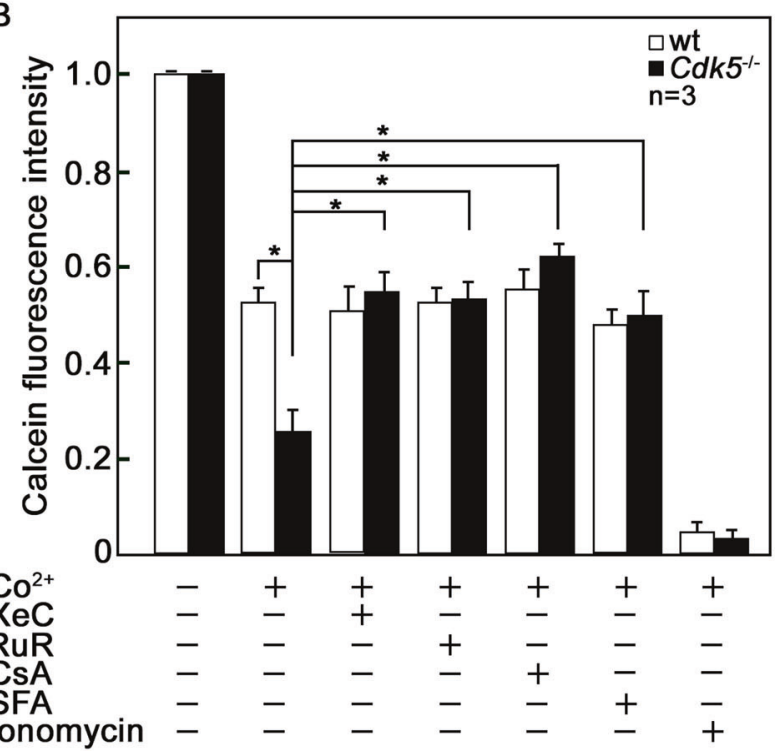

Fig. 5 Inhibition of IP3R by xestospongin $\mathrm{C}(\mathrm{XeC})$ or $\mathrm{MCU}$ by ruthenium red (RuR) reverses the opening of $\mathrm{mPTP}$ in $\mathrm{Cdk5}^{-/-}$ MEFs. a Wt and $C d k 5^{-/-}$MEFs pretreated with or without $\mathrm{XeC}$ $(3 \mu \mathrm{M})$ or RuR $(3 \mu \mathrm{M})$ were loaded with calcein-AM, then treated with or without $\mathrm{CoCl}_{2}$. Cell were then analysed by flow cytometry. Cells treated with the potent $\mathrm{mPTP}$ desensitizers, cyclosporin A (CsA, $1 \mu \mathrm{M})$ or sanglifehrin A (SFA, $2 \mu \mathrm{M}$ ), were used as positive controls. b Quantitative analysis of the relative calcein fluorescence in wt and $C d k 5^{-/}$MEFs in the presence or absence of the treatments indicated above. Untreated cells and cells treated with ionomycin served as controls. Values are means \pm SEM from three $(n=3)$ independent experiments. ${ }^{*} p<0.05$ by unpaired Student's $t$ test.

further characterize the specific role of MAM Cdk5 in ERmitochondria tethering, our finding that inhibition of either $\mathrm{ER} \mathrm{Ca}^{2+}$ release with $\mathrm{XeC}$ or mitochondrial calcium uptake with RuR blocks the increase in MPTP opening induced by Cdk5 loss suggests that elevated mitochondrial calcium influx underlies the increase in MPTP opening in the absence of Cdk5. Altogether, our studies demonstrate a novel mechanism whereby Cdk5 controls mPTP opening by regulating the formation of ER-mitochondria contact site structures and subsequently, calcium transfer from the ER to the mitochondria and $\left[\mathrm{Ca}^{2+}\right]_{\mathrm{mt}}$ level.

\section{Materials and methods}

\section{Materials}

Dulbecco's modified eagle's medium (DMEM), heatinactivated fetal bovine serum (FBS), EDTA-Trypsin, antibiotic-antimycotic, Calcein AM, Fluo-4 AM and Rhod-2 AM were from Life Technologies Inc. The protease inhibitor cocktail, Cyclosporine A (CsA), Ruthenium Red (RuR), ATP, carbonyl cyanide-p-trifluoromethoxyphenylhydrazone (FCCP) and Xestospongin $\mathrm{C}(\mathrm{XeC})$ were from Sigma. Antibodies to Cdk5 (C-8), FACL-4 (F-4), VDAC1 (B-6), GRP78 (A-10), PCNA (PC-10) and LDH-A (E-9) were from Santa Cruz Biotech. Sanglifehrin A (SFA) was a gift from Novartis (Switzerland).

\section{Primary MEF isolation and culture}

Primary MEFs were isolated from E13.5 wt and $C d k 5^{-1-}$ mouse embryos following the protocol described by Durkin et al. [35] which was based on the method by Todaro and Green [36] and subsequent modifications of the technique by Coats et al. [37]. Embryos were from $C d k 5^{+/-}$pregnant female mice crossed with $C d k 5^{+/-}$male mice. Embryos were washed with (phosphate-buffered saline) PBS, decapitated and eviscerated then washed again with PBS. Embryos were minced with sterile forceps and placed in $3-5 \mathrm{ml}$ of $0.05 \%$ trypsin-EDTA, pipetted up and down to get cells into suspension and incubated at $37^{\circ} \mathrm{C}$ for $5 \mathrm{~min}$. Cell suspensions were transferred to new tubes containing MEF medium (DMEM-high glucose supplemented with 10\% FBS, 1\% penicillin-streptomycin and $2 \mathrm{mM}$ GlutaMAX) then centrifuged at 1,000 rpm for $5 \mathrm{~min}$. Cell pellets were resuspended in fresh media and plated in $10 \mathrm{~cm}$ cell culture dishes. Primary MEFs were cultured in DMEM supplemented with 10\% FBS and $100 \mathrm{U} / \mathrm{ml}$ each of penicillin and streptomycin under hypoxic condition $\left(5 \% \mathrm{O}_{2}\right.$ and $5 \% \quad \mathrm{CO}_{2}$ incubator). All experiments were performed in passage P2-P7 MEFs.

\section{Transmission electron microscopy}

TEM analysis was performed following fixation, dehydration, infiltration, and embedding of wt and $C d \mathrm{k}^{-/-}$MEFs in situ. Ultra-thin $(\sim 60 \mathrm{~nm})$ sections were cut and stained with $2 \%$ uranyl acetate and lead citrate and observed under a Hitachi H7650 TEM at the University of Calgary's Microscopy and Imaging Facility. Images were acquired through an AMT 16000 CCD mounted on the microscope. 


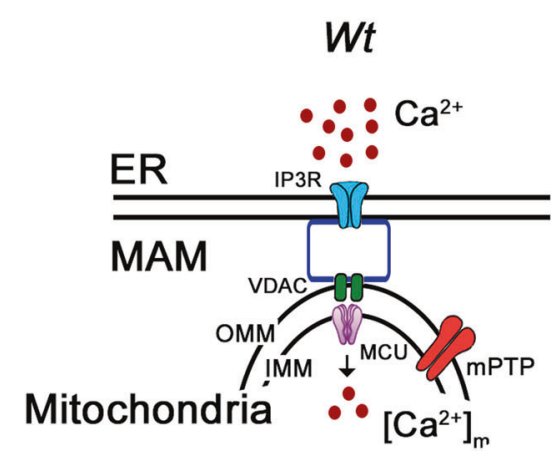

Fig. 6 Proposed model illustrating mPTP opening in wt and $\mathrm{Cdk5}^{-/-}$MEFs. Loss of Cdk5 that localizes in MAM causes reduced distance between ER and mitochondria, and increased number and

\section{MAM and mitochondria isolation}

Crude and pure MAMs, and mitochondria were isolated using Percoll density gradient centrifugation as described previously [38]. Briefly, trypsinized MEFs were homogenized in $10 \mathrm{ml}$ of $\mathrm{IB}_{\text {cells }}-1$ buffer containing $225 \mathrm{mM}$ mannitol, $75 \mathrm{mM}$ sucrose, $0.1 \mathrm{mM}$ EGTA, and $30 \mathrm{mM}$ Tris- $\mathrm{HCl}(\mathrm{pH} 7.4)$. Homogenates $(\mathrm{H})$ were centrifuged at $600 \times \mathrm{g}$ for $5 \mathrm{~min}$ at $4{ }^{\circ} \mathrm{C}$. The resulting supernatants were subjected to further centrifugation at $7000 \times g$ for $10 \mathrm{~min}$ at $4{ }^{\circ} \mathrm{C}$. Pellets were resuspended in $10 \mathrm{ml}$ of $\mathrm{IB}_{\text {cells }}-2$ buffer containing $225 \mathrm{mM}$ mannitol, $75 \mathrm{mM}$ sucrose and $30 \mathrm{mM}$ Tris- $\mathrm{HCl}(\mathrm{pH}$ 7.4) followed by centrifugation at $7000 \times g$ for $10 \mathrm{~min}$ at $4{ }^{\circ} \mathrm{C}$. Pellets containing MAM and mitochondria were resuspended again in $10 \mathrm{ml}$ of $\mathrm{IB}_{\text {cells }}-2$ buffer and centrifuged at $10,000 \times \mathrm{g}$ for $10 \mathrm{~min}$ at $4{ }^{\circ} \mathrm{C}$. The resulting pellets were resuspended in $2 \mathrm{ml}$ of mitochondria resuspending buffer (MRB: $250 \mathrm{mM}$ mannitol, $0.5 \mathrm{mM}$ EGTA and $5 \mathrm{mM}$ HEPES, $\mathrm{pH}$ 7.4). The crude mitochondria were then layered with $8 \mathrm{ml}$ of Percoll medium $[225 \mathrm{mM}$ mannitol, $25 \mathrm{mM}$ HEPES (pH 7.4), $1 \mathrm{mM}$ EGTA and $30 \%$ Percoll] and $4 \mathrm{ml}$ of MRB then centrifuged at $95,000 \times g$ for $30 \mathrm{~min}$ at $4{ }^{\circ} \mathrm{C}$. Pure mitochondria (MT) settles at the bottom of the tube while the MAM fraction appears as a white band above the MT fraction. The MAM and MT fractions were each resuspended in $14 \mathrm{ml}$ of MRB buffer and centrifuged at $6300 \times g$ for $10 \mathrm{~min}$ at $4{ }^{\circ} \mathrm{C}$. The resulting supernatants $(\sim 14 \mathrm{ml})$ of the MAM fraction, designated as crude MAM (C-MAM), were further subjected to centrifugation at $100,000 \times g$ for $1 \mathrm{hr}$. Pellets containing pure MAM (P-MAM) or pure MT were each resuspended in $50 \mu \mathrm{l}$ of MRB buffer.

\section{Western blotting}

Isolated subcellular fractions $(50 \mu \mathrm{l})$ were loaded in $12.5 \%$ SDS polyacrylamide gels and transferred onto nitrocellulose membranes. Membranes were blocked in 5\% skimmed milk
$C d k 5^{--}$

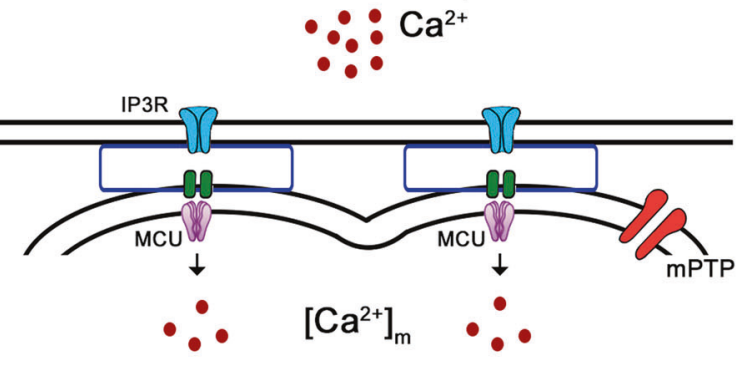

length of ER-mitochondria contact sites, causing increased $\mathrm{Ca}^{2+}$ transfer from the ER to the mitochondria, which leads to increased $\left[\mathrm{Ca}^{2+}\right]_{\mathrm{mt}}$ and subsequently, mPTP opening.

then incubated with the indicated primary antibody (1:1000 dilution) at $4{ }^{\circ} \mathrm{C}$ overnight. After washing with Trisbuffered saline (TBS) + Tween-20 (TBST) $\quad(50 \mathrm{mM}$ Tris-HCl, pH 7.6, 0.1\% Tween-20, 0.8\% NaCl), membranes were incubated with horseradish peroxidaseconjugated secondary antibody (1:10,000 dilution) for $1 \mathrm{~h}$. Immunoreactive bands were detected using ECL reagent (Amersham).

\section{mPTP opening assay}

Calcein fluorescence was measured using the Image-IT live mitochondria permeability transition pore assay kit (Thermo Fisher Sci.) as per the manufacturer's protocol. Briefly, cells seeded on a four-chamber cover glass (Lab-Tek) were loaded with calcein AM $(1 \mu \mathrm{M})$, MitoTracker Red $(200 \mathrm{nM})$, treated with or without $\mathrm{CoCl}_{2}(1 \mathrm{mM})$ in Hank's balanced salt solution (HBSS), and incubated for $15 \mathrm{~min}$ at $37^{\circ} \mathrm{C}$ under $5 \% \mathrm{CO}_{2}$. Cells were then washed with HBSS buffer and images were taken under an Olympus $1 \times 71$ fluorescence microscope using a $\times 10$ objective with or without the $\times 1.6$ magnification changer.

For flow cytometry, cells $\left(1 \times 10^{4}\right)$ were harvested using Trypsin-EDTA and pre-incubated with CsA $(1 \mu \mathrm{M})$, SFA $(2 \mu \mathrm{M}), \mathrm{XeC}(3 \mu \mathrm{M})$ or RuR $(3 \mu \mathrm{M})$ for $1 \mathrm{~h}$ then stained as indicated above. Cells were then washed with HBSS, resuspended in ice-cold PBS and analyzed by flow cytometry using a fluorescein isothiocyanate filter $(530 \mathrm{~nm})$ for measuring calcein fluorescence.

\section{Calcium measurement}

For cytoplasmic $\mathrm{Ca}^{2+}$ measurements, MEFs seeded on $3.5 \mathrm{~cm}$ glass bottom petri dishes (80\% confluency) were loaded with Fluo-4 AM $(5 \mu \mathrm{M})$ in HBSS (with $1.26 \mathrm{mM}$ calcium) for $30 \mathrm{~min}$ at RT. Cells were washed three times with KRH buffer $(125 \mathrm{mM} \mathrm{NaCl}, 5 \mathrm{mM} \mathrm{KCl}, 1.2 \mathrm{mM} \mathrm{MgCl}, 25 \mathrm{mM}$ HEPES, $6 \mathrm{mM}$ glucose) then subjected to single cell calcium 
imaging using a Leica TCS SP8 confocal microscope $(\times 20$ objective). Fluorescence signals were quantified as ratio $(F /$ $F_{0}$ ) of the fluorescence after addition of FCCP, relative to the basal fluorescence $\left(F_{0}\right)$ before stimulation.

For mitochondrial $\mathrm{Ca}^{2+}$ measurements, MEF cells seeded on $3.5 \mathrm{~cm}$ glass bottom petri dishes ( $80 \%$ confluency) were loaded with Rhod-2 AM $(5 \mu \mathrm{M})$ in $\mathrm{KRH}$ buffer (125 mM NaCl, $5 \mathrm{mM} \mathrm{KCl,} 25 \mathrm{mM}$ HEPES, $6 \mathrm{mM}$ glucose) for $30 \mathrm{~min}$ at RT. Cells washed three times with KRH buffer were subjected to single cell calcium imaging using a Zeiss LSM 510 Meta laser scanning confocal microscope $(\times 20$ objective). Fluorescence signals were quantified as ratio $\left(F / F_{0}\right)$ of the fluorescence after addition of ATP, relative to the basal fluorescence $\left(F_{0}\right)$ before stimulation.

\section{Statistical analysis}

Student's $t$ test (unpaired, two-sided) was used. Significance was set at $p<0.05$.

Acknowledgements We thank Novartis Pharma AG for providing SfA. This work was supported in part by grants from the CIHR (MOP123400) and NSERC (RGPIN/06270-2019) to KYL and an Alberta Cancer Foundation graduate studentship to SN.

\section{Compliance with ethical standards}

Conflict of interest The authors declare that they have no conflict of interest.

Publisher's note Springer Nature remains neutral with regard to jurisdictional claims in published maps and institutional affiliations.

Open Access This article is licensed under a Creative Commons Attribution 4.0 International License, which permits use, sharing, adaptation, distribution and reproduction in any medium or format, as long as you give appropriate credit to the original author(s) and the source, provide a link to the Creative Commons license, and indicate if changes were made. The images or other third party material in this article are included in the article's Creative Commons license, unless indicated otherwise in a credit line to the material. If material is not included in the article's Creative Commons license and your intended use is not permitted by statutory regulation or exceeds the permitted use, you will need to obtain permission directly from the copyright holder. To view a copy of this license, visit http://creativecommons. org/licenses/by/4.0/.

\section{References}

1. Sun KH, de Pablo Y, Vincent F, Shah K. Deregulated Cdk5 promotes oxidative stress and mitochondrial dysfunction. J Neurochem. 2008;107:265-78.

2. Qu D, Rashidian J, Mount MP, Aleyasin H, Parsanejad M, Lira A, et al. Role of Cdk5-mediated phosphorylation of Prx2 in MPTP toxicity and Parkinson's disease. Neuron. 2007;55:37-52.

3. Fitzgerald JC, Camprubi MD, Dunn L, Wu HC, Ip NY, Kruger R, et al. Phosphorylation of HtrA2 by cyclin-dependent kinase- 5 is important for mitochondrial function. Cell Death Differ. 2012;19:257-66.

4. Meuer K, Suppanz IE, Lingor P, Planchamp V, Goricke B, Fichtner L, et al. Cyclin-dependent kinase 5 is an upstream regulator of mitochondrial fission during neuronal apoptosis. Cell Death Differ. 2007;14:651-61.

5. Weishaupt JH, Kussmaul L, Grotsch P, Heckel A, Rohde G, Romig $\mathrm{H}$, et al. Inhibition of CDK5 is protective in necrotic and apoptotic paradigms of neuronal cell death and prevents mitochondrial dysfunction. Mol Cell Neurosci. 2003;24:489-502.

6. NavaneethaKrishnan S, Rosales JL, Lee KY. Loss of Cdk5 in breast cancer cells promotes ROS-mediated cell death through dysregulation of the mitochondrial permeability transition pore. Oncogene. 2018;37:1788-804.

7. Giorgi C, Marchi S, Pinton P. The machineries, regulation and cellular functions of mitochondrial calcium. Nat Rev Mol Cell Biol. 2018;19:713-30.

8. Paupe V, Prudent J. New insights into the role of mitochondrial calcium homeostasis in cell migration. Biochem Biophys Res Commun. 2018;500:75-86.

9. Grimm S. The ER-mitochondria interface: the social network of cell death. Biochim Biophys Acta. 2012;1823:327-34.

10. Rizzuto R, Marchi S, Bonora M, Aguiari P, Bononi A, De Stefani $\mathrm{D}$, et al. $\mathrm{Ca}(2+)$ transfer from the ER to mitochondria: when, how and why. Biochim Biophys Acta. 2009;1787:1342-51.

11. Vance JE. MAM (mitochondria-associated membranes) in mammalian cells: lipids and beyond. Biochim Biophys Acta. 2014;1841:595-609.

12. Wiedemann N, Meisinger C, Pfanner N. Cell biology. Connecting organelles. Science. 2009;325:403-4.

13. Hayashi T, Rizzuto R, Hajnoczky G, Su TP. MAM: more than just a housekeeper. Trends Cell Biol. 2009;19:81-88.

14. Tagaya M, Arasaki K. Regulation of mitochondrial dynamics and autophagy by the mitochondria-associated membrane. Adv Exp Med Biol. 2017;997:33-47.

15. Ortiz-Sandoval CG, Hughes SC, Dacks JB, Simmen T. Interaction with the effector dynamin-related protein 1 (Drp1) is an ancient function of Rab32 subfamily proteins. Cell Logist. 2014;4: e986399.

16. Patergnani S, Missiroli S, Marchi S, Giorgi C. Mitochondriaassociated endoplasmic reticulum membranes microenvironment: targeting autophagic and apoptotic pathways in cancer therapy. Front Oncol. 2015;5:173.

17. Bravo-Sagua R, Rodriguez AE, Kuzmicic J, Gutierrez T, LopezCrisosto C, Quiroga C, et al. Cell death and survival through the endoplasmic reticulum-mitochondrial axis. Curr Mol Med. 2013;13:317-29.

18. Ma JH, Shen S, Wang JJ, He Z, Poon A, Li J, et al. Comparative proteomic analysis of the mitochondria-associated ER membrane (MAM) in a long-term type 2 diabetic rodent model. Sci Rep. 2017;7:2062.

19. Michel AH, Kornmann B. The ERMES complex and ERmitochondria connections. Biochem Soc Trans. 2012;40:445-50.

20. Csordas G, Varnai P, Golenar T, Roy S, Purkins G, Schneider TG, et al. Imaging interorganelle contacts and local calcium dynamics at the ER-mitochondrial interface. Mol Cell. 2010;39:121-32.

21. Patergnani S, Suski JM, Agnoletto C, Bononi A, Bonora M, De Marchi E, et al. Calcium signaling around Mitochondria Associated Membranes (MAMs). Cell Commun Signal. 2011;9:19.

22. Shoshan-Barmatz V, De S, Meir A. The mitochondrial voltagedependent anion channel 1, $\mathrm{Ca}(2+)$ transport, apoptosis, and their regulation. Front Oncol. 2017;7:60.

23. Rizzuto R, Brini M, Murgia M, Pozzan T. Microdomains with high $\mathrm{Ca} 2+$ close to IP3-sensitive channels that are sensed by neighboring mitochondria. Science. 1993;262:744-7. 
24. Rizzuto R, Pinton P, Carrington W, Fay FS, Fogarty KE, Lifshitz $\mathrm{LM}$, et al. Close contacts with the endoplasmic reticulum as determinants of mitochondrial $\mathrm{Ca} 2+$ responses. Science. 1998;280:1763-6.

25. Decuypere JP, Monaco G, Missiaen L, De Smedt H, Parys JB, Bultynck G. IP(3) receptors, mitochondria, and $\mathrm{Ca}$ signaling: implications for aging. J Aging Res. 2011;2011:920178.

26. Liu Y, Zhu X. Endoplasmic reticulum-mitochondria tethering in neurodegenerative diseases. Transl Neurodegener. 2017;6:21.

27. Gomez-Suaga P, Paillusson S, Stoica R, Noble W, Hanger DP, Miller CCJ. The ER-mitochondria tethering complex VAPBPTPIP51 regulates autophagy. Curr Biol. 2017;27:371-85.

28. Finkel T, Menazza S, Holmstrom KM, Parks RJ, Liu J, Sun J, et al. The ins and outs of mitochondrial calcium. Circ Res. 2015;116:1810-9.

29. Duchen MR. Mitochondria and calcium: from cell signalling to cell death. J Physiol. 2000;529(Pt 1):57-68.

30. Contreras L, Drago I, Zampese E, Pozzan T. Mitochondria: the calcium connection. Biochim Biophys Acta. 2010;1797:607-18.

31. Altschuld RA, Hohl CM, Castillo LC, Garleb AA, Starling RC, Brierley GP. Cyclosporin inhibits mitochondrial calcium efflux in isolated adult rat ventricular cardiomyocytes. Am J Physiol. 1992;262:H1699-1704.

32. Ichas F, Jouaville LS, Mazat JP. Mitochondria are excitable organelles capable of generating and conveying electrical and calcium signals. Cell. 1997;89:1145-53.

33. Kinnally KW, Peixoto PM, Ryu SY, Dejean LM. Is mPTP the gatekeeper for necrosis, apoptosis, or both? Biochim Biophys Acta. 2011;1813:616-22.

34. Lemasters JJ, Qian T, He L, Kim JS, Elmore SP, Cascio WE, et al. Role of mitochondrial inner membrane permeabilization in necrotic cell death, apoptosis, and autophagy. Antioxid Redox Signal. 2002;4:769-81.

35. Durkin ME, Qian X, Popescu NC, Lowy DR. Isolation of mouse embryo fibroblasts. Bio Protoc 2013;3:e908.

36. Todaro GJ, Green H. Quantitative studies of the growth of mouse embryo cells in culture and their development into established lines. J Cell Biol. 1963;17:299-313.

37. Coats S, Whyte P, Fero ML, Lacy S, Chung G, Randel E, et al. A new pathway for mitogen-dependent cdk2 regulation uncovered in p27(Kip1)-deficient cells. Curr Biol. 1999;9:163-73.

38. Wieckowski MR, Giorgi C, Lebiedzinska M, Duszynski J, Pinton P. Isolation of mitochondria-associated membranes and mitochondria from animal tissues and cells. Nat Protoc. 2009;4:1582-90.

39. Ohshima T, Ward JM, Huh CG, Longenecker G, Veeranna, Pant $\mathrm{HC}$, et al. Targeted disruption of the cyclin-dependent kinase 5 gene results in abnormal corticogenesis, neuronal pathology and perinatal death. Proc Natl Acad Sci USA. 1996;93:11173-8.

40. Petronilli V, Miotto G, Canton M, Colonna R, Bernardi P, Di Lisa F. Imaging the mitochondrial permeability transition pore in intact cells. Biofactors. 1998;8:263-72.

41. Lemasters JJ, Theruvath TP, Zhong Z, Nieminen AL. Mitochondrial calcium and the permeability transition in cell death. Biochim Biophys Acta. 2009;1787:1395-401.

42. Giaime E, Yamaguchi H, Gautier CA, Kitada T, Shen J. Loss of DJ-1 does not affect mitochondrial respiration but increases ROS production and mitochondrial permeability transition pore opening. PLoS ONE 2012;7:e40501.
43. Giacomello M, Pellegrini L. The coming of age of the mitochondria-ER contact: a matter of thickness. Cell Death Differ. 2016;23:1417-27.

44. Rizzuto R, De Stefani D, Raffaello A, Mammucari C. Mitochondria as sensors and regulators of calcium signalling. Nat Rev Mol Cell Biol. 2012;13:566-78.

45. Naon D, Scorrano L. At the right distance: ER-mitochondria juxtaposition in cell life and death. Biochim Biophys Acta. 2014;1843:2184-94.

46. Raffaello A, Mammucari C, Gherardi G, Rizzuto R. Calcium at the center of cell signaling: interplay between endoplasmic reticulum, mitochondria, and lysosomes. Trends Biochem Sci. 2016;41:1035-49.

47. Pozzan T, Rudolf R. Measurements of mitochondrial calcium in vivo. Biochim Biophys Acta. 2009;1787:1317-23.

48. Kaczmarek-Hajek K, Lorinczi E, Hausmann R, Nicke A. Molecular and functional properties of $\mathrm{P} 2 \mathrm{X}$ receptors-recent progress and persisting challenges. Purinergic Signal. 2012;8:375-417.

49. Smith JB, Smith L, Higgins BL. Temperature and nucleotide dependence of calcium release by myo-inositol 1,4,5-trisphosphate in cultured vascular smooth muscle cells. J Biol Chem. 1985;260:14413-6.

50. Solanes P, Heuze ML, Maurin M, Bretou M, Lautenschlaeger F, Maiuri $\mathrm{P}$, et al. Space exploration by dendritic cells requires maintenance of myosin II activity by IP3 receptor 1 . EMBO J. 2015;34:798-810.

51. Gafni J, Munsch JA, Lam TH, Catlin MC, Costa LG, Molinski TF, et al. Xestospongins: potent membrane permeable blockers of the inositol 1,4,5-trisphosphate receptor. Neuron. 1997;19:723-33.

52. Moore CL. Specific inhibition of mitochondrial $\mathrm{Ca}++$ transport by ruthenium red. Biochem Biophys Res Commun. 1971; 42:298-305.

53. Crompton M, Ellinger $\mathrm{H}$, Costi A. Inhibition by cyclosporin A of a $\mathrm{Ca}^{2+}$-dependent pore in heart mitochondria activated by inorganic phosphate and oxidative stress. Biochem J. 1988;255:357-60.

54. Clarke SJ, McStay GP, Halestrap AP. Sanglifehrin A acts as a potent inhibitor of the mitochondrial permeability transition and reperfusion injury of the heart by binding to cyclophilin-D at a different site from cyclosporin A. J Biol Chem. 2002;277:34793-9.

55. Batandier C, Leverve X, Fontaine E. Opening of the mitochondrial permeability transition pore induces reactive oxygen species production at the level of the respiratory chain complex I. J Biol Chem. 2004;279:17197-204.

56. Halestrap AP. What is the mitochondrial permeability transition pore? J Mol Cell Cardiol. 2009;46:821-31.

57. Poston CN, Krishnan SC, Bazemore-Walker CR. In-depth proteomic analysis of mammalian mitochondria-associated membranes (MAM). J Proteom. 2013;79:219-30.

58. Rowland AA, Voeltz GK. Endoplasmic reticulum-mitochondria contacts: function of the junction. Nat Rev Mol Cell Biol. 2012;13:607-25.

59. Csordas G, Renken C, Varnai P, Walter L, Weaver D, Buttle KF, et al. Structural and functional features and significance of the physical linkage between ER and mitochondria. J Cell Biol. 2006; 174:915-21.

60. Rieusset J. The role of endoplasmic reticulum-mitochondria contact sites in the control of glucose homeostasis: an update. Cell Death Dis. 2018;9:388. 